\title{
A CONTRIBUIÇÃO DO GNOTHI SEAUTON PARA A EDUCAÇÃO*
}

\author{
Barbara Marques Merlin \\ Universidade Metodista de São Paulo (UMESP) São Bernardo do Campo - SP
}

\begin{abstract}
RESUMO
0 presente texto tem como objetivo adjuntar à máxima délfica gnothi seauton (conhece-te a ti mesmo) como auxílio para a educação contemporânea. Este preceito foi apresentado por Michel Foucault (2018) em um de seus cursos no Collège de France no ano de 1981-1982 intitulado como A hermenêutica do sujeito. Foucault utilizará como eixo de seu curso o diálogo socrático O primeiro Alcibíades (2016) para demonstrar a relação entre mestre e discípulo em uma ótica do cuidado de si.

A educação nos dias atuais tem passado por momentos de incertezas, das quais professores e alunos se distanciam cada vez mais, este distanciamento por incrível que pareça, interfere no desenvolvimento dos alunos em sala de aula, sobretudo no ensino médio em que os adolescentes estão em momento de reconhecimento e busca pela própria identidade, a proposta é trazer este preceito para a contemporaneidade afim de reaproximar professores de alunos.

O conhece-te a ti mesmo será, portanto, o fio condutor para encontrar o caminho dessa aproximação entre ambos, será por esta relação do cuidado de si que o reencontro consigo mesmo será possível dentro e fora da sala de aula. Para que isso seja
\end{abstract}

* Trabalho apresentado pela SEFIME: Semana de filosofia na UMESP , São Bernardo do Campo, SP, 11-14 nov. 2019.

** Graduanda em filosofia pela Universidade Metodista de São Paulo (UMESP) E:mail: Barbara.marques.mm@gmail.com 
possível, percorreremos tais caminhos; (i) entender o conceito de gnothi seauton e (ii) o cuidado de si como estratégia para a educação nos dias atuais.

Palavras-chave: Gnothi Seauton; Foucaul; cuidado de si; educação; identidade

\section{INTRODUÇÃo}

Pensar em educação na contemporaneidade é pensar em diversos fatores como: política, identidade, sociedade, etc. Mas ainda é difícil pensar na aproximação entre professor e aluno, há uma necessidade gritante nos adolescentes em busca de sua identidade, em se descobrirem perante os meios em que estão inseridos, meios esses que são conflitantes, e a sua construção vai lidar justamente com esses vários meios, como o familiar, escolar e até mesmo o de valores, em que cada ambiente diferente se tem um tipo de valor.

0 contexto familiar desses alunos interfere fortemente na vida de cada um e a mesma, se constitui perante sua história de vida, sobretudo com suas relações familiares, no entanto, a escola constitui como outro contexto de desenvolvimento, ela pode criar outras relações com os alunos que diferencie o tipo dessas mesmas relações que o adolescente tem na família, com isso estes adolescentes de diferentes idades, aprendem a agir diferente em função do contexto.

As escolas, portanto, podem construir relações com os alunos de acordo com aquele contexto e não só imaginar que o aluno irá reproduzir na escola relações que ela tem na família, entendendo que, o aluno trás consigo essa bagagem da família, porém não se limitaria a isso, e que faz parte dos potenciais do sujeito articular-se diferentemente aos contextos em que eles se inserem, logo, a educação se faz uma alternativa à educação familiar.

Pensando nesses aspectos, seria possível fazer uma educação para todos? Independente de sua origem social, lugar de nascimento, etc. E ao mesmo tempo uma educação para cada um, ou seja, uma escola que consiga dar conta de uma educação que responde ao direito social, portanto, a uma demanda social de uma sociedade que é mais democrática e mais justa, e que ao mesmo tempo seja uma educação escolar que faça sentido pra cada um dos estudantes que tem acesso à escola. 
Contudo, para que haja uma educação para cada um, uma educação que faça realmente sentido para esses alunos, é preciso uma relação saudável com seu próprio professor. A não satisfação do professor nas instituições em que trabalham pode chegar a um burnout prejudicando sua atividade. Codo (2000, p. 241) apresenta o burnout como estresse laboral, como o mal que afeta, com maior freqüência nos profissionais da área da educação e saúde. O professor neste contexto se envolve efetivamente com seus alunos, com as instituições e entra em um burnout. 0 burnout é acarretado por todo desgaste emocional gerado durante todo um dia ou uma vida de docência.

Esse descontentamento afeta diretamente o aluno, e será neste exato momento em que ambos os lados se encontram em desânimo, o professor não querendo mais estar em sala de aula e o aluno muito menos.

0 conhece - te a ti mesmo, vem acoplado com o de cuidado de si (epimeléia heauton), só é possível conhecer-se pelo cuidado de si, e só há possibilidade no cuidado pelo conhecer-se. Portanto, é essencial que para tratar de um preceito, deverá tratar sobre o outro conseqüentemente, haja vista de que ambos não se faz sozinho é preciso que tenha o Outro, é na relação com o outro que consegue-se praticar e enraizar o epimeleia heauton.

0 cuidado de si (e daqui em diante tratarei apenas como "cuidado de si", mas que remeto também ao "conhece-te a ti mesmo") é rememorado por Foucault (2018) em seus cursos ministrados na década de 80 no Collège de France, cursos estes, que ficaram conhecidos como fazendo parte do terceiro Foucault, o que é pensado na ética.

0 pensador irá buscar desde os Gregos e trazendo para a modernidade a importância do cuidado de si, sobretudo na relação consigo perante o outro. 0 epiméleia heautou (cuidado de si) é uma prática, uma introspecção, uma forma de retiro e, principalmente o cuidado com a alma. E como já visto, esta prática não pode ser feita sozinho, tem que haver o outro, aquele que cuida do cuidado do outro, que o motiva, o faz pensar, o transforma em tempos de sua própria transformação.

É um momento em que quando um pensa em desistir o outro pega pela mão e mostra toda a sua volta os motivos para ele não desistir, (não entrar em burnout). Mas não só isso, o cuidado de si 
implica em diversos fatores aos quais deverão ser realizados de forma que não cesse, o exercício do cuidado de si exige permanência. Será, portanto, neste trabalho de si sobre si que ambos os sujeitos envolvidos passam a entender o que é a arte de viver, entenderem que a relação que se presa a alteridade ${ }^{1}$, é, sobretudo uma relação que valha a pena se lutar para continuar a existir, pelo outro e por si.

A proposta neste texto é com o cuidado de si, conseguir pensar em uma relação promissora entre professor e aluno, tendo em vista todos os obstáculos diários, mas que pela afetividade consegue desviar o olhar para quem realmente precisa, ou seja, ele mesmo.

\section{O CONCEITo de GNothi SEAUton}

O cuidado de si é o ato de ocupar-se consigo, de preocupar-se consigo (FOUCAULT. 2018 p.4) "Pode-se objetar que, para estudar as relações entre sujeito e verdade, é sem dúvida um tanto paradoxal e passavelmente sofisticada escolher a noção de epimelia heautou para qual a historiografia da filosofia, até o presente, não concedeu maior importância. "A relação entre sujeito e verdade é uma peça fundamental para a reflexão do preceito originário gnothi seauton (conhece - te a ti mesmo) o qual foi gravado na pedra do templo de Délfos, conceito este que aparece atrelado ao epimeleia heautou (cuida de ti mesmo) é necessário que cuide de ti mesmo, é será nesse aspecto que aparecerá o preceito conhece-te a ti mesmo.

O epimeleia heautouserá considerado o momento do despertar, o qual passa a enxergar o mundo novamente ou pela primeira vez, e principalmente em ações feitas de si para si mesmo em práticas de subjetividade. 0 epimeleia heautou possui outras formas de ser traduzida como "ocupar-se consigo mesmo, recolher-se em si, sentir prazer em si mesmo, buscar deleite somente em si, permanecer em companhia de si mesmo, ser amigo de si mesmo, respeitar-se, etc." (FOUCAULT. 2018 p.13), mas que todos englobam uma única prática, o cuidado de si.

Conceito este que Emmanuel Lèvinas deu vida em sua obra a Totalidade do Infinito. Alteridade é a relação que um sujeito constrói com o outro e de forma totalmente gratuita para tal cf. A TOTALIDADE DO INFINITO.

Revista Páginas de Filosofia, v. 8, n. 1-2, p. 79-85, jan/dez. 2019 
Contudo, o cuidado de si também não se faz sozinho, é preciso que haja o outro, um mestre que o guie para despertá-lo, não há cuidado de si sem o mestre que o coloque em estímulo novamente

Diferentemente do professor, ele não cuida de ensinar aptidões e capacidade a quem ele guia, não procura ensiná-lo a falar nem a prevalecer sobre os outros, etc. 0 mestre é aquele que cuida do cuidado que o sujeito tem de si mesmo e que, no amor que tem pelo seu discípulo, encontra a possibilidade de cuidar do cuidado que o discípulo tem de si próprio, amando o rapaz de forma desinteressada, ele é assim o princípio e o modelo do cuidado que o rapaz deve ter de si enquanto sujeito. (FOUCAULT. 2018 p.55)

O cuidado de si, sobretudo implica no cuidado com a alma, quando o indivíduo ocupa de ti mesmo, estará ocupando de sua própria alma, cuidar da alma enquanto sujeito de ação e que se serve de seu corpo. Quando Foucault traz a expressão "Governo de si e dos outros" está chamando atenção justamente para este cuidado da alma, ou seja, não se pode governar uma cidade sem que ao menos o indivíduo se governe, se conheça, é preciso obter uma autodireção, logo, governo de si (epimeléia heautou) governo dos outros (parrhésia ${ }^{2}$ ). Portanto, é uma ocupação por toda uma vida, sua função crítica vai acentuar-se cada vez mais, e terá um papel corretivo, ou ainda a prática de si se torna cada vez mais uma atividade crítica em relação a si mesmo, ao seu mundo cultural, à vida dos outros.

Assim sendo, a prática de si com a fórmula geral da arte de viver (tékne tou bíou), é a aproximação pela qual o cuidado de si não aparecia mais como uma forma de condição preliminar ao que depois viria a ser uma arte de viver.

\section{CONSIDERAÇõES FINAIS}

Como pode ser visto até aqui, o cuidado de si acontece de forma efetiva a partir do outro e que ao mesmo tempo estará cuidado de si

2 Parrhésia significa "falar franco" ou "tudo dizer", esta noção Michel Foucault dará vida no seus últimos cursos no Collège de France cf. A CORAGEM DA VERDADE. 
próprio, ora no diálogo socrático $O$ primeiro Alcibíades (2006) Sócrates mostra ao jovem Alcíbiades que há muito além do que ele pensava saber e que seria por si próprio que o mesmo alcançaria tais conhecimentos, ele "ensinava" à pensar.

Pensar na educação contemporânea é pensar no modo em que vivemos na sociedade no qual estamos inseridos. Quantos alunos e quantos professores estão em sala de aula que possuem uma maneira de viver totalmente diferente da outra? Muitos.

Então porque não pensar em uma educação em que haja afeto? No qual o professor esteja na escola pelo aluno, pensando nessa maneira de viver o qual ele é inserido e trazer para dentro da sala de aula, mesmo com todas as suas dificuldades pessoais, pelo desgaste pessoal, mas que esteja ali determinado a ajudar aquele aluno. 0 cuidado de si é um modo sublime de pensar ou até mesmo repensar sobre si mesmo, e sobre a vida, sobretudo junto com os que estão à sua volta. Portanto, conhecer-se é uma forma de conhecer o outro em especial as necessidades que o outro à sua frente tem perante a sociedade em que vive.

0 cuidado de si pode parecer romântico, mas existe coisa pior do que um aluno estar em sala de aula e o professor que está ali dando aula não o enxergar? Muitos dali não irão para uma universidade se não tiver um incentivo diário, que mostre que este mesmo aluno é capaz, como já visto o contexto familiar conta muito, mas a escola terá o papel fundamental também na educação desde mesmo aluno.

Portanto, desistir de si não está incluído no pacote do gnothi seauton, desistir do outro muito menos, é preciso ter coragem, alteridade, afeto, empatia, ânimo de estar todos os dias em sala de aula lidando com pessoas diferentes de você mesmo e entender que será nesta relação que o próprio sujeito será construído e de forma que valerá a pena.

0 epimeleia heaton se torna uma estratégia para educação atual, no sentido de colocar em prática aquele professor que estava adormecido dentro dele mesmo, e que consegue despertar os seus alunos, ser docente não é para qualquer um, exige brio, vontade, querer fazer a mudança todos os dias, mesmo tendo cansaço, mas sabe que tem um compromisso com todos aqueles que o espera na parte da manhã, tarde e noite. 
O cuidado de si na educação é isso, é comprometimento consigo, com ele e com todos ali inseridos à sua volta, se ter hombridade é ser romântico, então o que falta é o amor por si e pelo outro. Cuide-se!

\section{REFERÊNCIAS}

CODO, Wanderley. (coord.) Educação: carinho e trabalho. 2000. Petrópolis/RJ. Vozes. Conf. Nacional dos trabalhadores em educação/Universidade de Brasília.

FOUCAULT, Michel. A hermenêutica do sujeito. Tradução de Márcio Alves da Fonseca e Salma Tannus Muchail. Obra completa. 2018. São Paulo. Martins Fontes.

, Michel. A coragem da verdade. Tradução de Eduardo Brandão. Obra completa. 2017. São Paulo/SP. Martins Fontes

LÈVINAS, Emmanuel. Totalidade do infinito. Tradução de José Pinto Ribeiro. Obra completa. 2008. São Paulo/SP. Edições 70. 